\title{
Implementasi dan Analisis Fitur Keamanan Protokol MQTT pada Telehealthcare
}

\author{
Dian Rachmadini ${ }^{1}$ Ira Puspasari $^{2}$ Jusak $^{3}$ \\ Program Studi/Jurusan Teknik Komputer, Universitas Dinamika \\ Email:16410200026@dinamika.ac.id ${ }^{1}$,ira@dinamika.ac.id², jusak@dinamika.ac.id ${ }^{3}$
}

\begin{abstract}
Abstrak: Protokol MQTT merupakan salah satu protokol IoT dengan konsep publisher, subscriber, dan broker. Penerapan protokol MQTT dengan fitur keamanan dapat menggunakan Transport Layer Security (TLS). Pada makalah ini, fitur keamanan TLS pada MQTT akan diimplementasikan untuk mengirim data sinyal EKG. Sinyal EKG berbeda setiap orang dan merupakan privasi bagi pasien, karena dari sinyal EKG ini juga dapat digunakan untuk melihat penyakit pasien tersebut. Proses transmisi pada MQTT Security (MQTTS) akan menggunakan file kunci yang telah dibuat oleh broker. File kunci ini akan diberikan kepada client supaya bisa melakukan komunikasi, mengirim dan menerima data yang telah terenkripsi. Enkripsi data dilakukan karena adanya file kunci ini sehingga proses transmisi lebih aman. Hasil analisis perhitungan selisih besar paket sebelum dan setelah pengiriman pada QoS 0 adalah 152,6458 byte dan 139,4504 byte. Sedangkan QoS 1 sebesar 99,7932 byte dan 115,5321 byte. Kedua QoS menunjukkan selisih yang cukup besar, tetapi disisi lain pegiriman data menjadi lebih aman. Pada pengujian waktu yang diperlukan untuk proses enkripsi, QoS 0 menghasilkan waktu rata-rata 0,7 ms, QoS 1 menunjukkan hasil lebih lama yaitu 9,6 ms dikarenakan penambahan sinyal kontrol pada QoS 1. Hasil uji integritas data dengan cross-correlation, QoS 0 dan QoS 1 menunjukkan nilai 1 pada lag ke-0 yang artinya data yang dikirim dan diterima tidak terdapat perubahan (sama).
\end{abstract}

Kata Kunci: Protokol MQTT, MQTT Secure, Sinyal EKG.

\begin{abstract}
MQTT protocol is one of the widely used lightweight IoT protocols. To secure the data transmission, the protocol enables security features by employing transport layer security (TLS). In this paper, such MQTT security (MQTTS) will be implemented to transmit electrocardiogram (ECG) data. Indeed, ECG data contains a unique identification of a person, thus its security should be maintained properly. To achieve that goal, transmission process on the MQTTS utilizes key files that have been created by the broker. This key file will be transmitted to the client so that they can communicate, send and receive the encrypted data. In this study, we measured the effect of encryption on the packet length, computation time and data integrity by activating both QoS 0 and QoS 1. Examination results showed that packet sizes before and after encryption for QoS 0 were 152.6458 bytes and 139.4504 bytes, consecutively. On the other hand, packet sizes for QoS 1 were 99.7932 bytes before encryption and 115.5321 bytes after encryption. It showed that for both QoS, the packet size growing larger yet the data enjoyed more secure transmission. Evaluation on the encryption processing time showed an average time of $0.7 \mathrm{~ms}$ for QoS $O$ and a longer processing time i.e., $9.6 \mathrm{~ms}$ for QoS 1. This is mainly due to the addition of control signals in QoS 1 . Data integrity was tested using the cross-correlation function. The study showed that for both QoS 0 and QoS 1 indicated a cross-correlation of 1 at the Oth lag. It can be concluded that the sent and the received data are exactly the same.
\end{abstract}

Keywords: MQTT Protocol, MQTT Secure, Electrocardiogram (ECG)

\section{PENDAHULUAN}

Konsep Internet of Things atau biasa dikenal dengan IoT saat ini sudah tidak asing lagi, berbagai bidang pekerjaan dan aktifitas manusia menjadi lebih ringan dan terbantu karena menerapkan konsep ini. Salah satu protokol yang digunakan untuk IoT adalah protokol Message Queue Telemetry Transpor (MQTT) [1]. Protokol MQTT memiliki konsep yang sederhana yang terdiri dari publisher, broker, dan subscriber. Ketiganya saling dihubungkan dengan topik yang menentukan si penerima data. Subscriber hanya akan menerima data dari publisher yang memiliki topik sama. Pembuatan topik tidak dibatasi dan dibuat di sisi publisher.

Pada tahun 2019, M. Reza Bintami [2] melakukan penelitian dengan menerapkan protokol MQTT untuk pengiriman sinyal Heartrate. Sinyal Heartrate merupakan bagian dari sinyal EKG, dimana pada penelitian tersebut implementasi protocol MQTT dilakukan dengan analisis pengiriman data memanfaatkan fitur QoS 0 dan QoS 1. Penelitian ini menunjukkan hasil bahwa penggunaan protokol MQTT pada

parameter packet loss dan delay tergolong sangat bagus, karena packet loss yang dihasilkan kurang dari $1 \%$ dan rata-rata delay 20,21 ms pada Qos 1, sehingga 
memungkinkan untuk diterapkan pada pengiriman data real-time, termasuk yang dilakukan pada penelitian ini.

Pada penelitian sebelumnya pengamanan data sinyal EKG dilakukan oleh Bramasta Agnanda Setiawan (2018) dengan metode anonimasi dan menggunakan algoritma Jusak-Seedahmed untuk mengembalikan struktur sinyal EKG setelah proses anonimasi. Proses anonimasi dilakukan dengan dengan menguraikan data dalam domain frekuensi. Anonimasi ini dilakukan dengan tujuan mengamankan data sinyal EKG dalam jaringan internet. Selanjutnya, penelitian ini dilanjutkan oleh Sony Solehuddin mengenai rekontruksi sinyal hasil dari proses anonimasi tersebut Proses ini diawali dengan mengambil kunci terenkripsi yang disimpan pada cloud server. Pembuatan kunci ini diperoleh dari frekuensi rendah pada proses anonimasi. Proses rekonstruksi dilakukan berdasarkan algoritma FFT (Fast Fourier Transform) dengan melakukan transformasi bagian sinyal EKG dari cloud server dari domain waktu ke dmain frekuensi [3].

Pada tahun 2018, Ayaskanta Mishra[4] juga melakukan penelitian sistem pemantauan EKG jarak jauh berbasis MQTT menggunakan Raspberry pi, Modul AD8232 dan ADS1115. Broker MQTT yang digunakan adalah CloudMQTT yang merupakan broker online

Pada tahun 2019, Hyunwoo Lee melakukan penelitian, dengan judul "MQTLS: Toward Secure MQTT Communication with an Untrusted Broker". MQTLS ini merupakan protokol berbasis OpenSSL yang ditujukan untuk membatasi broker supaya tidak membaca pesan apa pun dari publisher, kecuali topik untuk pengiriman pesan[5]. Pada tahun yang sama penelitian mengenai MQTTS juga dilakukan oleh Neven Nikolov[6] dengan menggunakan sensor DHT22.

Pada tahun 2020, Adrian Febiyanto[7] melakukan penelitian mengenai pengamatan sinyal jantung EKG, dimana pada penelitian ini sinyal EKG akan dipantau dengan mengirimkan data pada firebase yang diakses secara real-time. Sistem pengiriman menggunakan node sensor berupa raspberry pi kemudian dari firebase akan dikirim ke aplikasi berbasis mobile.

Pada penelitian ini, protokol MQTT akan diterapkan pada pengiriman data EKG (Elektrokardiogram) yang merupakan data rekam aktifitas kelistrikan jantung. Penerapan protokol ini dengan mengaktifkan fitur keamanan pada MQTT yaitu dengan menggunakan protokol TLS. Protokol MQTT dan TLS biasa disebut dengan MQTTS. Penggunaan fitur keamanan ini dikarenakan data sinyal EKG merupakan data yang bersifat unik dan berbeda setiap individu.

Pada penelitian ini dilakukan analisis terhadap 3 parameter yaitu : selisih besar paket data sebelum enkripsi dan sesudah enkripsi, selisih waktu yang dibutuhkan sebelum pengiriman dan sesudah pengiriman, dan pengujian integritas data.

\section{METODE PENELITIAN}

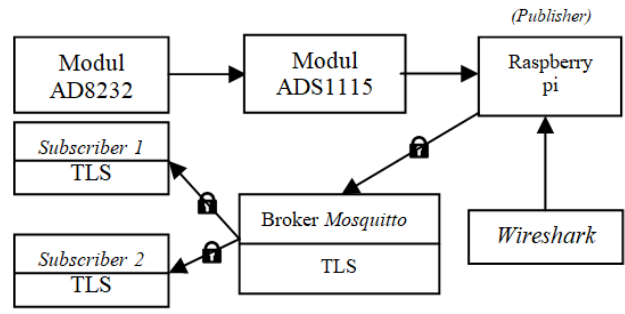

Gambar 1. Rancangan Penelitian

Berdasarkan gambar 1 di atas, terdapat modul AD8232, modul ADS1115 dan raspberry pi yang merupakan node sensor dan berperan sebagai publisher. Data yang dikirim berupa sinyal EKG yang sudah terenkripsi, dikarenakan pada saat pengiriman sudah menyertakan file kunci ca.crt yang sudah terpasang pada

klien.

\section{Perangkat Node Sensor}

Node sensor pada penelitian ini terdiri dari beberapa komponen sebagai berikut :

a. Modul AD8232

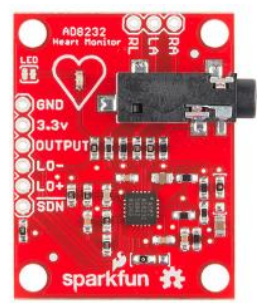

Gambar 2. Modul AD8232[7]

Modul AD8232 merupakan modul sensor Elektrokardiogram (EKG) yang bernilai analog. Untuk dapat mendeteksi sinyal jantung seseorang diperlukan elektroda penjapit.

b. Modul ADS1115

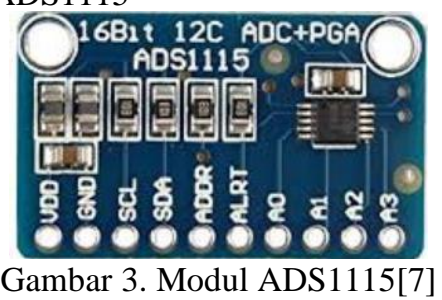

Modul ADS1115 merupakan modul adc (analog digital converter) 16 bit dengan tegangan sekitar 2,0-5,5 V. Modul ini juga memiliki fungsi PGA (Programmable Gain Amplifier) dimana fitur ini dapat memperkuat sinyal input analog pada saat pengambilan nilai ADC[7].

Modul ini digunakan untuk transfer data dari modul AD8232 ke raspberry pi supaya data sinyal EKG dapat terbaca pada Raspberry pi.

c. Raspberry pi

Seperti yang sudah banyak diketahui, Raspberry pi merupakan mini PC yang juga dapat 
menggabungkan fungsi komputer dan mikrokontroler. Pada penelitian ini Raspberry pi akan terhubung oleh modul AD8232 dan ADS1115 sebagai node sensor. Untuk dapat menerima data yang ditransfer oleh ADS1115 diperlukan mengaktifkan fungsi I2C pada Raspberry pi. Berikut skematik rangkaian untuk node sensor :

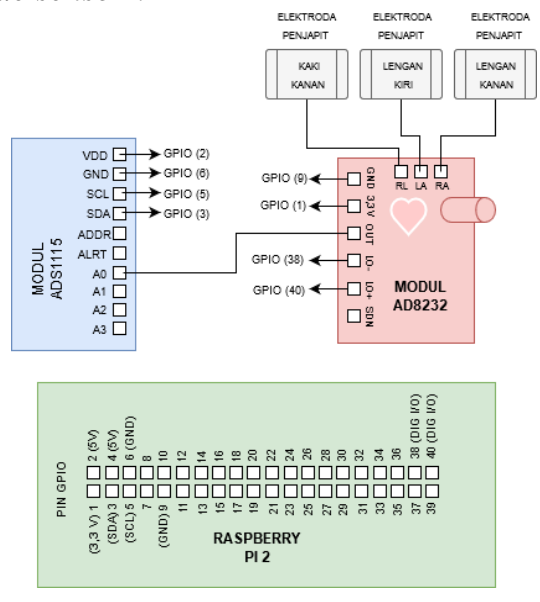

Gambar 4. Skematik Rangkaian Node Sensor

Gambar 4 di atas merupakan sambungan node sensor untuk pengambilan data sinyal EKG. Masing - masing elektroda penjapit terhubung dengan 3 pin modul ad8232 yaitu RL(Right Left), LA (Left Arm), RA (Right Arm). Kemudian pin OUT akan tersambung dengan pin A0 ADS1115 sehingga output akan ditransfer melalui I2C sehingga bisa terbaca oleh Rapberry pi.

\section{Sinyal Elektrokardiogram (EKG)}

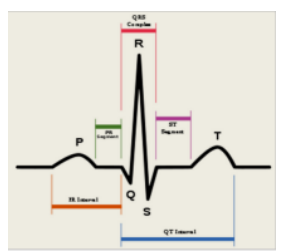

Gambar 5. Sinyal EKG[7]

Sinyal Elektrokardiogram (EKG) merupakan sinyal yang merekam aktifitas kelistrikan otot jantung. Perekaman sinyal ini menggunakan elektroda penjapit di lead yang ditentukan. Pada penelitian ini menggunakan 3 titik untuk mengambil data sinyal jantung tersebut, dimana elektroda penjapit tersebut diletakkan pada lengan tangan kanan, lengan tangan kiri, dan kaki kanan. Berikut titik peletakan elektroda penjapit :

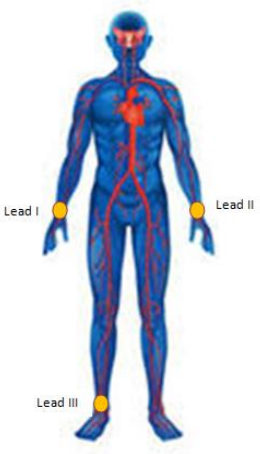

Gambar 6. Letak posisi elektroda penjapit

Seperti yang terlihat pada gambar 5, sinyal EKG terdiri dari 5 gelombang yaitu :

- Gelombang P adalah gelombang awal yang merupakan hasil depolarisasi di kedua atrium

- Gelombang Q merupakan gelombang defleksi negatif setelah gelombang $\mathrm{P}$

- Gelombang R merupakan gelombang defleksi positif setelah gelombang $\mathrm{P}$ atau setelah gelombang $\mathrm{Q}$.

- Gelombang S merupakan gelombang defleksi negatif setelah gelombang $\mathrm{R}$ atau gelombang $\mathrm{Q}$

- Gelombang T

merupakan hasil depolarisasi di kedua ventrikel. Normalnya positif dan inverted (terbalik) di aVR[8].

\section{File Kunci (ca.crt)}

Berdasarkan rangkaian penelitian pada gambar 1, data sinyal EKG yang telah dibaca oleh node sensor Raspberry pi akan langsung dikirim secara real-time ke kedua subscriber melalui broker mosquitto yang sudah terdapat file kunci (ca.crt).

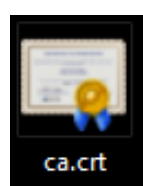

Gambar 7. File kunci ca.crt

Pada sisi publisher juga menyertakan file kunci (ca.crt) untuk mengirimkan data. Data yang dikirim langsung terenkripsi. Proses enkripsi data berpengaruh pada besar paket data. Lama waktu proses enkripsi juga akan dianalisis melalui hasil rekam pada wireshark dengan menghitung selisih waktu saat pengiriman dan waktu sebelum tertangkap oleh wireshark. Selanjutnya, broker hanya bisa meneruskan data dari client yang memiliki kunci yang sama sehingga setiap pengirim dan penerima harus menyertakan file kunci (ca.crt) tersebut. 
Pada sisi subscriber akan menerima data tersebut melalui terminal yang masing - masing sudah menggunakan fungsi dump untuk mengetahui besar paket data setelah didekripsi. Subscriber hanya menerima data yang sesuai dengan topik dan memiliki kunci yang sama. Pengiriman data akan dilakukan pada QoS 0 dan QoS 1. Dimana QoS 0 merupakan kualitas pelayanan yang hanya mengirimkan pesan tanpa memberi kepastian akan data sudah benar-benar tersampaikan atau tidak. Sedangkan pada QoS 1 data sudah terkirim dan tersampaikan dengan memberi feedback dari subscriber berupa SUBACK.

\section{Pembuatan Kunci}

Proses pembuatan file kunci (ca.crt) sendiri melalui openssl, dan dilakukan oleh broker. Kunci yang dibuat menggunakan algoritma enkripsi 3des, dengan panjang 2048 byte. Langkah - langkah pembuatan file kunci sebagai berikut:

1. Open directory openssl melalui terminal seperti berikut :

2. Membuat CA key pair untuk digunakan membuat CA certificate dengan syntax : "openssl genrsa -des3 -out ca.key 2048"

3. Membuat file CA certificate (ca.crt) akan digunakan untuk publish dan subscribe. Syntax

"openssl req -new -x509 -days 1826 -key ca.key -out ca.crt"

4. Membuat server key pair (server.key) yang akan digunakan oleh broker, dengan syntax: "openssl genrsa -out server.key 2048"

5. Kemudian membuat server certificate request (server.csr), dengan syntax:

"openssl req -new -out server.csr -key server.key"

6. Kemudian membuat server certificate (server.crt), dengan menggunakan file ca.crt untuk verifikasi dan menandatangani file server.crt. Syntax :

"openssl x509-req -in server.csr -CA ca.crt -cAkey ca.key -CA createserial out server.crt -days 360"

Setelah 6 file kuci tersebut dibuat. Kemudian masukkan cafile (ca.crt), certfile (server.crt, dan keyfile (server.key) pada mosquitto.conf seperti tampilan pada Gambar 8 berikut ini :

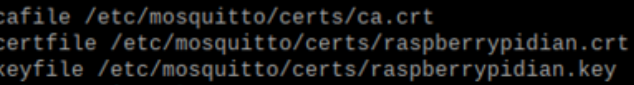

Gambar 8. File kunci pada mosquitto.conf

Nama certfile dan keyfile di sini ialah raspberrypidian.crt dan raspberrypidian.key.

\section{Pemasangan File Kunci pada Klien}

Setelah sudah dikonfigurasi pada mosquitto barulah membagikan file kunci ca.crt pada klien. Pemasangan file kunci pada klien menggunakan langkah -langkah berikut ini :

1. Broker membagikan file kunci ca.crt pada klien berupa PC

2. Cari Internet Options, akan muncul kotak dialog seperti dibawah ini :

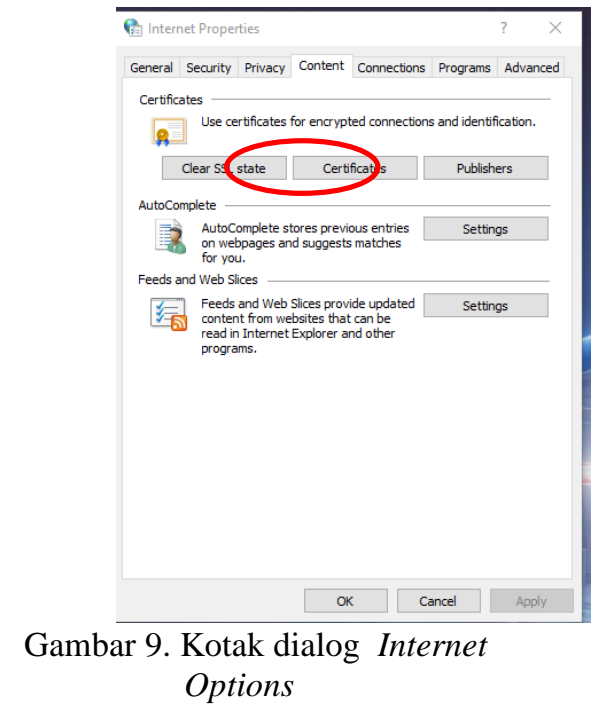

3. Kemudian klik certificates

4. Setelah itu klik import

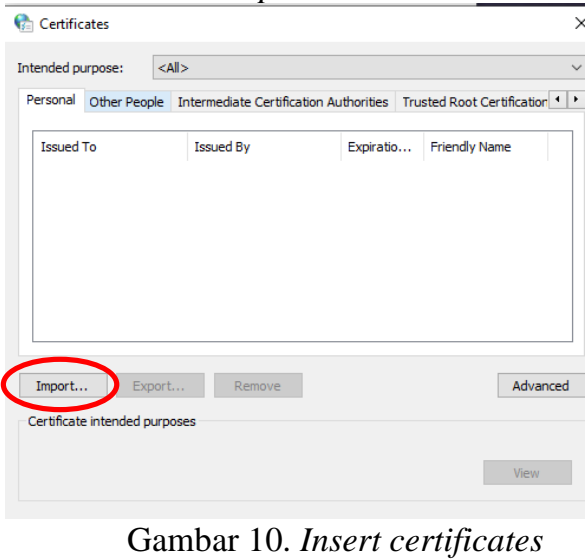

5. Kemudian arahkan directory file ca.crt 


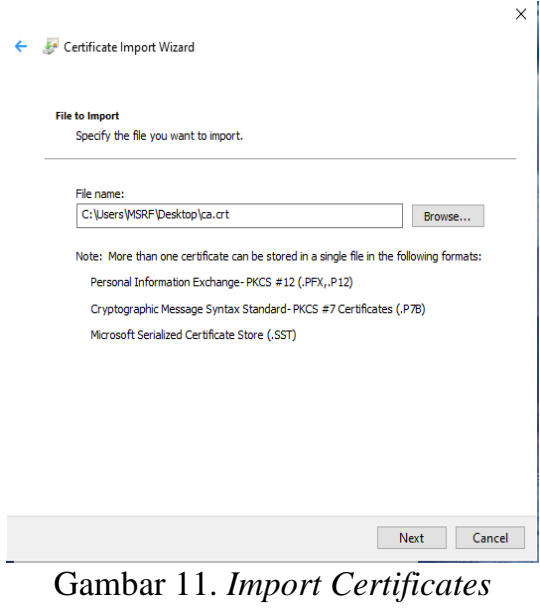

6. Kemudian klik Next $\rightarrow$ Install

7. Jika sudah selesai, klik finish

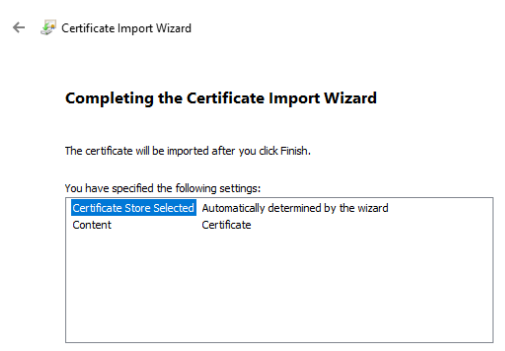

\section{Gambar 12. Certificate telah di-import}

Analisis data yang dilakukan pada penelitian ini meliputi 3 parameter yaitu :

1. Selisih besar paket data sebelum dan setelah pengiriman

2. Selisih waktu sebelum dan setelah pengiriman

3. Pengujian Integritas data menggunakan metode cross-correlation pada MATLAB

Perhitungan besar paket data bertujuan untuk mengetahui besar memori yang dibutuhkan untuk menggunakan MQTTS. Selisih waktu sebelum dan setelah pengiriman dilihat dari hasil rekam wireshark bertujuan untuk mengetahui rata-rata waktu yang dibutuhkan untuk proses enkripsi data pada MQTTS. Kemudian parameter ketiga yaitu pengujian integritas data dengan membandingkan data sebelum dikirim dan data setelah diterima menggunakan cross-correlation. Jika hasil lag ke-0 = 1 maka hasilnya sama, tidak berbeda meskipun data melewati proses enkripsi.

\section{HASIL DAN PEMBAHASAN}

Setelah melakukan pembuatan kunci pada broker dan pemasangan kunci pada klien. Percobaan pengiriman dapat dilakukan melalui terminal pada publisher dan subscriber dengan syntax sebagai berikut :
- Syntax Publisher

mosquitto pub -h 192.168.43.121 -t tes -d $\quad-p \quad 8883 \quad-$-cafile C: $\backslash$ Users $\backslash$ Asus $\backslash$ Desktop $\backslash c a . c r t$

- Syntax Subscriber

mosquitto sub -h 192.168.43.121 -t tes -d $\quad-p \quad 8883 \quad-$-cafile c: $\backslash$ Users $\backslash$ Asus $\backslash$ Desktop $\backslash$ ca.crt

Keterangan :

a. pub/sub merupakan perintah publish atau subscribe

b. - $\mathrm{h}$ merupakan host atau alamat broker yang dituju

c. -t merupakan topik yang digunakan

d. -d merupakan dump untuk mengetahui besar paket yang diterima, QoS yang digunakan, dan proses koneksi broker-klien

e. - p merupakan port yang digunakan. MQTTS terletak pada port 8883

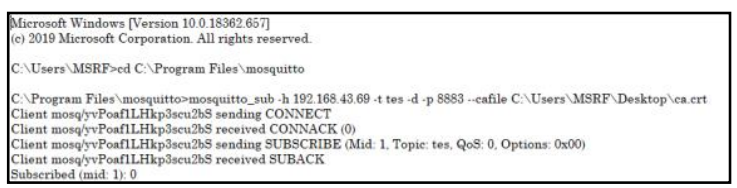

Gambar 13. Subscriber sudah terhubung dengan Broker

f. - -cafile merupakan letak file kunci ca.crt yang digunakan

1. Percobaan Pengiriman pada Setiap QoS Tes pengiriman pesan pada setiap QoS, dilakukan dengan menambahkan syntax "-q" dan hasilnya seperti Gambar 14 berikut ini :

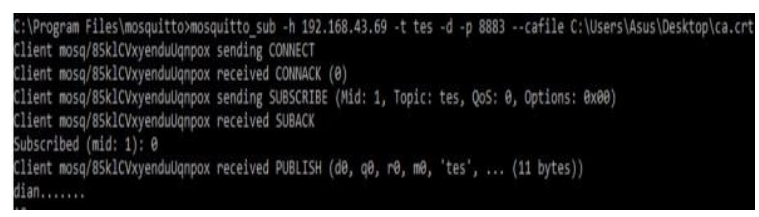

Gambar 14. Pengiriman pada QoS 0

Perintah subscribe tanpa menuliskan syntax untuk QoS, maka akan otomatis menggunakan QoS 0 seperti gambar 14 diatas. Dari Gambar 14 diatas sinyal kontrol yang terdapat pada QoS 0 adalah PUBLISH kemudian dilanjutkan pesan yang diterima. Sinyal kontrol PUBLISH adalah pesan yang mewakili publikasi baru/terpisah.

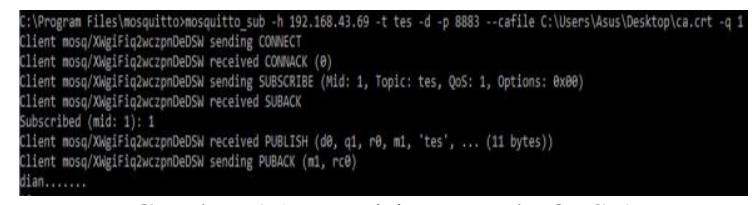

Gambar 15. Pengiriman pada QoS 1

Pengiriman pada QoS 1 terdapat 2 sinyal kontrol yaitu : PUBLISH dan PUBACK, kemudian diikuti oleh pesan yang diterima. 
PUBLISH sendiri sama dengan QoS 0, sedangkan PUBACK merupakan respons QoS 1 terhadap pesan publikasi. Pada setiap pengiriman baik QoS 0,1 , atau 2 akan terlihat besar paket yang diterima, seperti yang terlihat pada gambar 14 dan 15 besar paket yang diterima adalah sebesar 11 byte. Data ini nantinya akan digunakan untuk analisis perbandingan paket data sebelum dan setelah terenkripsi.

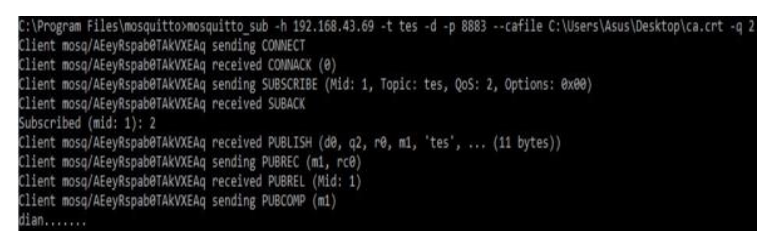

Gambar 16. Pengiriman pada QoS 2

Pada QoS 2 terdapat 4 sinyal kontrol yang digunakan yaitu : PUBLISH, PUBREC, PUBREL, dan PUBCOMP. PUBLISH terdapat di semua level QoS. Sinyal kontrol PUBREC merupakan bagian pertama dari aliran pesan QoS 2, PUBREL merupakan bagian kedua, dan PUBCOMP merupakan bagian terakhir dari aliran QoS 2, kemudian diikuti oleh pesan yang diterima. Apabila dari sisi subscriber tidak menerima sampai bagian terakhir dari QoS 2 (PUBCOMP) maka akan dikirimkan sinyal lagi supaya PUBCOMP tersampaikan pada subscriber. Alur protokol pada protokol QoS 2 memerlukan waktu yang sedikit lama dibanding dengan QoS 0 dan QoS 1.

Pada penelitian ini tidak dilakukan pengiriman menggunakan QoS 2 dikarenakan waktu setiap pengirimannya yang lama sehingga menyebabkan beberapa data hilang (lost). Tetapi disamping itu, kualitas pelayanan pada QoS 2 sangat terjamin bahwa data benar-benar tersampaikan pada sisi penerima dan pesan diterima 1 kali (tidak berulang).

\section{Hasil Pengiriman pada QoS 0}

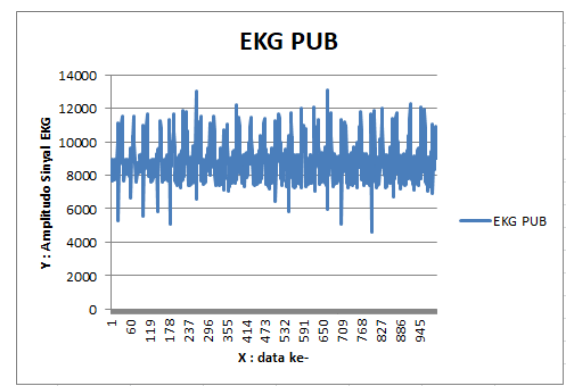

Gambar 17. Sinyal EKG sampel ke-1 yang dikirim

Pengiriman menggunakan sample sebanyak 10 orang dengan masing-masing 1000 data yang dikirim secara real-time, dan kedua subscriber menerima secara bersamaan.

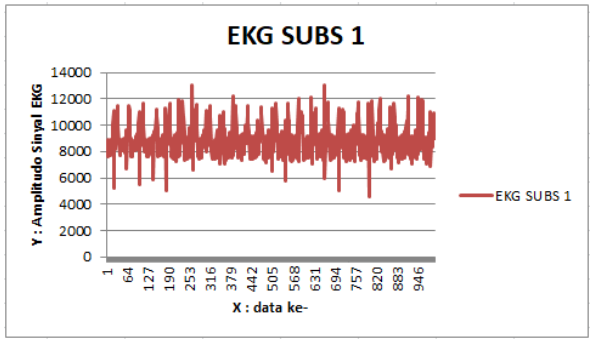

Gambar 18. Sinyal EKG sampel ke-1 pada Subscriber 1

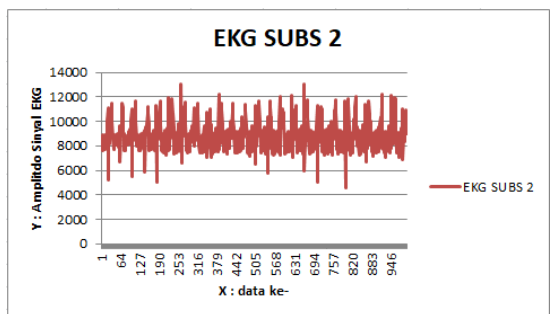

Gambar 19. Sinyal EKG sampel-1 pada Subcriber 2

Dari hasil pengirim dan penerimaan data pada kedua subscriber, dapat dilihat bahwa tidak ada perbedaan data yang signifikan berdasarkan grafik sinyal diatas.

a. Analisis Data

- Selisih besar paket kedua subscriber

$>$ Subscriber 1

Tabel 1 Besar Paket Sebelum Enkripsi QoS 0

\begin{tabular}{cccc}
\hline $\begin{array}{c}\text { No } \\
\text { Sampel }\end{array}$ & \multicolumn{3}{c}{ Besar Paket } \\
$\begin{array}{c}\text { Min } \\
\text { (byte) }\end{array}$ & $\begin{array}{c}\text { Max } \\
\text { (byte) }\end{array}$ & $\begin{array}{c}\text { Rata- rata setiap } \\
\text { sampel (byte) }\end{array}$ \\
\hline 1 & 4 & 5 & 4,142 \\
2 & 4 & 5 & 4,135 \\
3 & 4 & 5 & 4,088 \\
4 & 4 & 5 & 4,12 \\
5 & 4 & 5 & 4,161 \\
6 & 4 & 5 & 4,119 \\
7 & 4 & 5 & 4,004 \\
8 & 4 & 5 & 4,298 \\
9 & 4 & 5 & 4,009 \\
10 & 4 & 5 & 4,164 \\
Min/Max & 4 & 5 & \\
Standar & & & 0,0834 \\
Deviasi & & & 4,124 \\
Rata-rata & & & \\
\hline
\end{tabular}

Tabel 2 Besar Paket Setelah Enkripsi QoS 0

\begin{tabular}{cccc}
\hline \multirow{2}{*}{$\begin{array}{c}\text { No } \\
\text { Sampel }\end{array}$} & $\begin{array}{c}\text { Min } \\
\text { (byte) }\end{array}$ & $\begin{array}{c}\text { Max } \\
\text { (byte) }\end{array}$ & $\begin{array}{c}\text { Rata- rata setiap } \\
\text { sampel (byte) }\end{array}$ \\
1 & 87 & 623 & 158,1918 \\
2 & 87 & 584 & 149,9449 \\
3 & 78 & 616 & 154,8506 \\
4 & 87 & 619 & 160,8387 \\
\hline
\end{tabular}




\begin{tabular}{cccc}
\hline 5 & 78 & 619 & 161,6364 \\
6 & 87 & 615 & 155,9046 \\
7 & 87 & 615 & 160,7799 \\
8 & 87 & 622 & 163,1738 \\
9 & 87 & 582 & 152,8293 \\
10 & 87 & 616 & 149,5476 \\
Min/Max & 78 & 623 & \\
Standar & & & 4,9222 \\
Deviasi & & & 156,7698 \\
Rata-rata & & & \\
\hline
\end{tabular}

Pada subscriber 1 minimum besar paket sebelum enkripsi adalah 4 byte dan maksimal 5 byte. Sedangkan minimum besar paket setelah enkripsi sebesar 78 byte dan maksimum 623 byte. Rata - rata besar paket sebelum enkripsi sebesar 4,124 byte dengan standar deviasi sebesar 0,0834 . Sedangkan rata-rata setelah enkripsi sebesar 156,7698 byte dengan standar deviasi sebesar 4,9222. Jika dihitung selisih rata-rata sebelum dan setelah enkripsi adalah 152,6458 byte.

\section{Subscriber 2}

Tabel 3 Besar Paket Sebelum Enkripsi QoS 0

\begin{tabular}{cccc}
\hline $\begin{array}{c}\text { No } \\
\text { Sampel }\end{array}$ & $\begin{array}{c}\text { Mesar Paket Sebelum Enkripsi } \\
\text { (byte) }\end{array}$ & $\begin{array}{c}\text { Max } \\
\text { (byte) }\end{array}$ & $\begin{array}{c}\text { Rata- rata setiap } \\
\text { sampel (byte) }\end{array}$ \\
\hline 1 & 4 & 5 & 4,142 \\
2 & 4 & 5 & 4,135 \\
3 & 4 & 5 & 4,088 \\
4 & 4 & 5 & 4,12 \\
5 & 4 & 5 & 4,161 \\
6 & 4 & 5 & 4,119 \\
7 & 4 & 5 & 4,004 \\
8 & 4 & 5 & 4,298 \\
9 & 4 & 5 & 4,009 \\
10 & 4 & 5 & 4,164 \\
Min/Max & 4 & 5 & \\
Standar & & & 0,0834 \\
Deviasi & & & 4,124 \\
Rata-rata & & & \\
\hline
\end{tabular}

Tabel 4 Besar Paket Setelah Enkripsi QoS 0

\begin{tabular}{cccc}
\hline \multirow{2}{*}{$\begin{array}{c}\text { Bo } \\
\text { Sampel }\end{array}$} & $\begin{array}{c}\text { Min } \\
\text { (byte) }\end{array}$ & $\begin{array}{c}\text { Max } \\
\text { (byte) }\end{array}$ & $\begin{array}{c}\text { Rata- rata setiap } \\
\text { sampel (byte) }\end{array}$ \\
1 & 87 & 483 & 146,4832 \\
2 & 87 & 620 & 140,7121 \\
3 & 87 & 285 & 141,2797 \\
4 & 87 & 652 & 147,5339 \\
5 & 87 & 615 & 147,4113 \\
6 & 87 & 484 & 142,7909 \\
7 & 87 & 615 & 145,1713 \\
8 & 87 & 622 & 144,4837 \\
9 & 87 & 516 & 139,7377 \\
10 & 87 & 621 & 140,1403 \\
Min/Max & 87 & 652 & \\
Standar & & & 3,0336 \\
Deviasi & & & \\
\hline
\end{tabular}

\begin{tabular}{ll}
\hline Rata-rata & 143,5744 \\
\hline
\end{tabular}

Hasil besar paket sebelum enkripsi subscriber 2 sama dengan subscriber 1. Sedangkan hasil minimum besar paket setelah enkripsi adalah 87 byte, dan maksimum 652 byte. Rata-rata besar paket setelah enkripsi 143,5744 byte, dengan standar deviasi sebesar 3,0336. Selisih rata-rata sebelum dan setelah enkripsi sebesar 139,4504 byte.

- Waktu yang dibutuhkan untuk proses enkripsi

Tabel 5 Waktu Enkripsi QoS 0

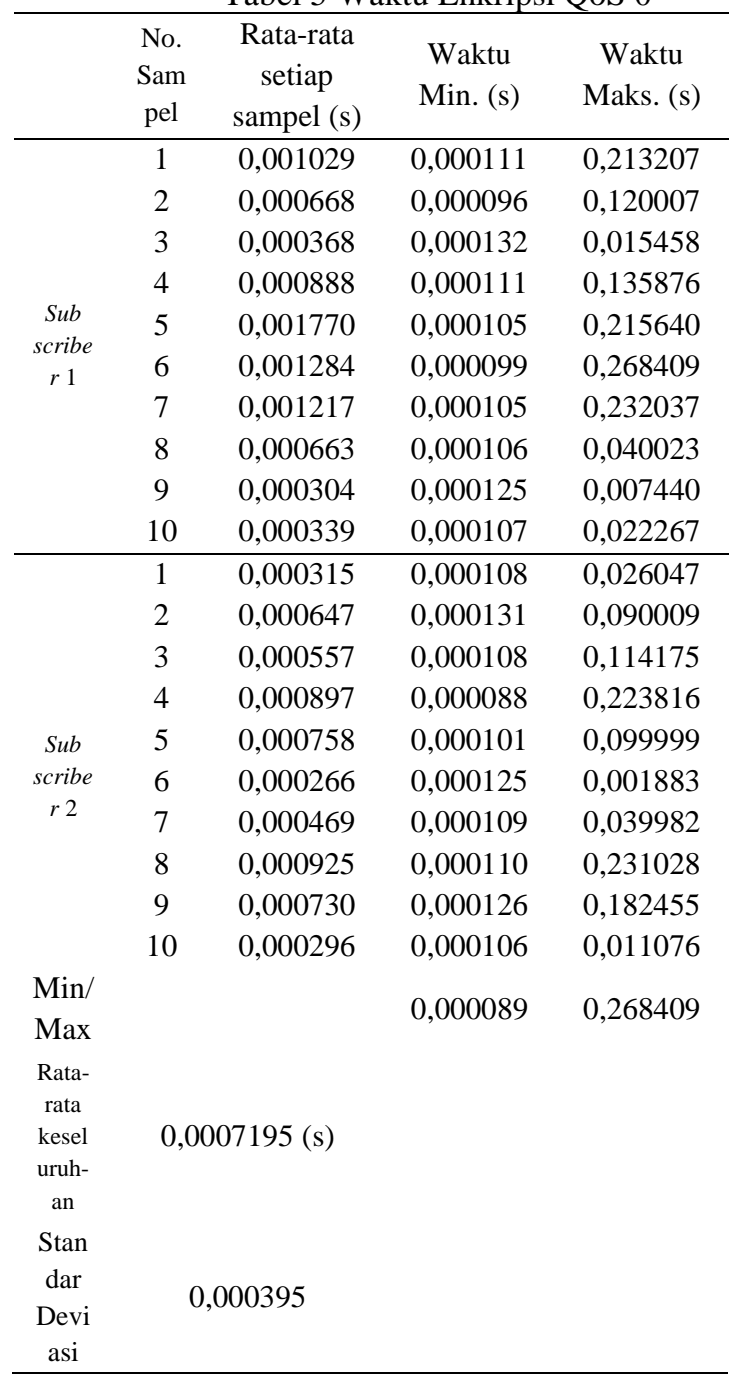

Pengiriman pada QoS 0 menghasilkan rata-rata keseluruhan dari kedua penerima yaitu 0,0007195 s. Dengan waktu minimum 0,000089 s dan maksimum 0,268409 s. Standar deviasi sebesar 0,000395 . 


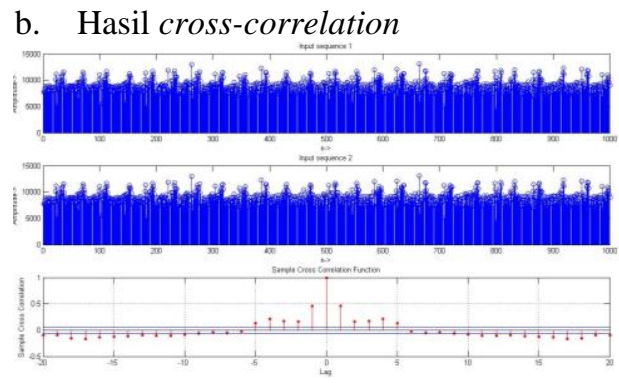

Gambar 20. Hasil Cross-correlation subscriber 1

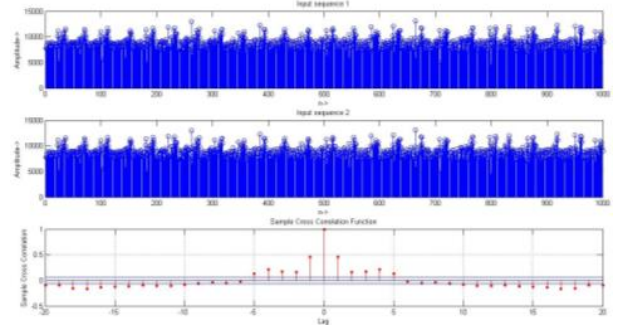

Gambar 21. Hasil Cross-correlation subscriber 2

Hasil uji cross-correlation pada kedua subscriber menunjukkan hasil 1 pada lag ke-0, sehingga dapat diartikan data yang dikirim dan diterima adalah sama meskipun setelah melalui proses enkripsi.

\section{Hasil Pengiriman pada QoS 1}

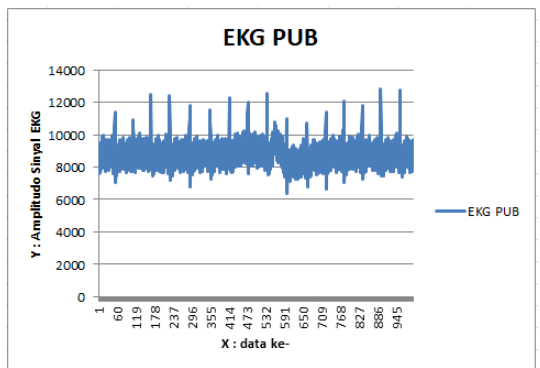

Gambar 22. Sinyal EKG sampel ke-10 yang dikirim

Tampilan Gambar 22 diatas merupakan salah satu dari 10 sampel data yang diambil. Sama halnya, dengan QoS 0 data antara pengirim dan penerima jika dilihat tidak ada perbedaan (sama).

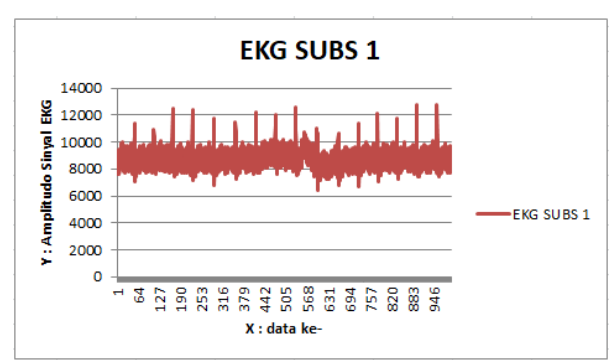

Gambar 23. Sinyal EKG sampel ke-10 pada penerima $1(\mathrm{QoS} 1)$

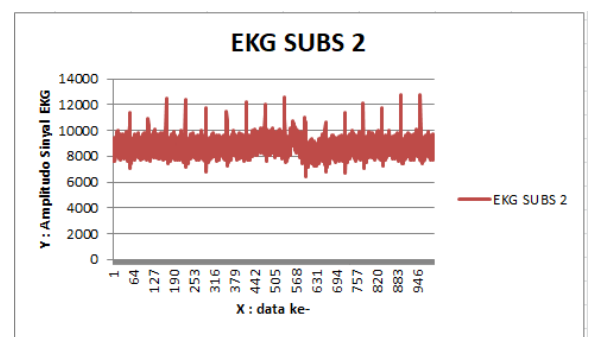

Gambar 24. Sinyal EKG sampel ke-10 pada penerima 2 (QoS 1)

a. Analisis Data

- Selisih besar paket kedua subscriber

- $\quad$ Subscriber 1

Tabel 6. Besar Paket Sebelum Enkripsi QoS 1

\begin{tabular}{cccc}
\hline $\begin{array}{c}\text { No } \\
\text { Sampel }\end{array}$ & $\begin{array}{c}\text { Besar Paket Sebelum Enkripsi } \\
\text { Min } \\
\text { (byte) }\end{array}$ & $\begin{array}{c}\text { Max } \\
\text { (byte) }\end{array}$ & $\begin{array}{c}\text { Rata- rata setiap } \\
\text { sampel (byte) }\end{array}$ \\
\hline 1 & 1 & 5 & 4,271 \\
2 & 4 & 5 & 4,403 \\
3 & 4 & 5 & 4,406 \\
4 & 4 & 5 & 4,401 \\
5 & 4 & 5 & 4,401 \\
6 & 4 & 5 & 4,417 \\
7 & 4 & 5 & 4,403 \\
8 & 4 & 5 & 4,421 \\
9 & 3 & 5 & 4,367 \\
10 & 4 & 5 & 4,061 \\
Min/Max & 1 & 5 & \\
Standar & & & 0,1122 \\
Deviasi & & & 4,3551 \\
Rata-rata & & &
\end{tabular}

Tabel 7 Besar Paket Setelah Enkripsi QoS 1

\begin{tabular}{cccc}
\hline \multirow{2}{*}{$\begin{array}{c}\text { No } \\
\text { Sampel }\end{array}$} & $\begin{array}{c}\text { Mesar Paket Setelah Enkripsi } \\
\text { (byte) }\end{array}$ & $\begin{array}{c}\text { Max } \\
\text { (byte) }\end{array}$ & $\begin{array}{c}\text { Rata- rata setiap } \\
\text { sampel (byte) }\end{array}$ \\
\hline 1 & 87 & 587 & 96,1483 \\
2 & 89 & 656 & 96,2053 \\
3 & 89 & 550 & 96,8126 \\
4 & 89 & 551 & 95,1161 \\
5 & 89 & 655 & 97,5437 \\
6 & 89 & 726 & 104,9597 \\
7 & 89 & 549 & 99,6813 \\
8 & 89 & 727 & 101,8016 \\
9 & 88 & 725 & 126,4734 \\
10 & 89 & 720 & 126,7407 \\
Min/Max & 87 & 727 & \\
Standar & & & 12,2068 \\
Deviasi & & & 104,1483 \\
Rata-rata & & &
\end{tabular}

Pengiriman QoS 1 pada subscriber 1 menghasilkan rata-rata sebelum enkripsi adalah 4,3551 byte. Besar paket sebelum enkripsi minimum adalah 1 byte dan maksimum 5 byte, dengan standar deviasi sebesar 0,1122 . Sedangkan besar paket setelah enkripsi menghasilkan minimum 87 byte dan maskimum 727 byte, dengan rata-rata 104,1483 byte. Standar deviasi yang dihasilkan sebesar 12,2068. Jika dihitung, selisih 
rata-rata antara sebelum dan setelah enkripsi sebesar 99,7932 byte.

\section{- $\quad$ Subscriber 2}

\begin{tabular}{cccc}
\multicolumn{4}{c}{ Tabel 8 Besar Paket Sebelum Enkripsi QoS 1 } \\
\hline $\begin{array}{c}\text { No } \\
\text { Sampel }\end{array}$ & $\begin{array}{c}\text { Mesar Paket } \\
\text { Min } \\
\text { (byte) }\end{array}$ & $\begin{array}{c}\text { Max } \\
\text { (byte) }\end{array}$ & $\begin{array}{c}\text { Rata- rata setiap } \\
\text { sampel (byte) }\end{array}$ \\
\hline 1 & 1 & 5 & 4,271 \\
2 & 4 & 5 & 4,403 \\
3 & 4 & 5 & 4,406 \\
4 & 4 & 5 & 4,401 \\
5 & 4 & 5 & 4,401 \\
6 & 4 & 5 & 4,417 \\
7 & 4 & 5 & 4,403 \\
8 & 4 & 5 & 4,421 \\
9 & 3 & 5 & 4,367 \\
10 & 4 & 5 & 4,061 \\
Min/Max & 1 & 5 & \\
Standar & & & 0,1122 \\
Deviasi & & & 4,3551 \\
Rata-rata & & & \\
\hline
\end{tabular}

Tabel 9 Besar Paket Sebelum Enkripsi QoS 1

\begin{tabular}{cccc}
\hline \multirow{2}{*}{$\begin{array}{c}\text { No } \\
\text { Sampel }\end{array}$} & $\begin{array}{c}\text { Besar Paket Setelah Enkripsi } \\
\text { (byte) }\end{array}$ & $\begin{array}{c}\text { Max } \\
\text { (byte) }\end{array}$ & $\begin{array}{c}\text { Rata- rata setiap } \\
\text { sampel (byte) }\end{array}$ \\
\hline 1 & 86 & 546 & 96,2407 \\
2 & 89 & 727 & 98,1434 \\
3 & 89 & 656 & 103,9379 \\
4 & 89 & 726 & 118,1540 \\
5 & 89 & 726 & 129,3213 \\
6 & 89 & 728 & 141,8834 \\
7 & 78 & 727 & 140,5599 \\
8 & 89 & 657 & 131,8484 \\
9 & 78 & 727 & 116,5707 \\
10 & 89 & 650 & 122,2121 \\
Min/ & 78 & 728 & \\
Max & & & 16,4958 \\
Standar & & & 119,8872 \\
Deviasi & & & \\
Rata- & & & \\
rata & & & \\
\hline
\end{tabular}

Pada subscriber 2 besar paket sebelum enkripsi sama dengan subscriber 1. Sedangkan besar paket setelah enkripsi minimum sebesar 78 byte dan maksimum 728 byte, dengan standar deviasi 16,4958. Rata-rata besar paket setelah enkripsi sebesar 119,8872 byte. Selisih rata-rata antara sebelum dan setelah enkripsi sebesar 115,5321 byte.

- Waktu yang diperlukan untuk proses enkripsi

Tabel 10 Waktu Enkripsi QoS 1

$\begin{array}{cccc}\text { No } & \text { Rata-rata } & \text { Waktu } & \text { Waktu } \\ \text { Sam } & \text { setiap } & \text { Min. (s) } & \text { Maks. (s) }\end{array}$

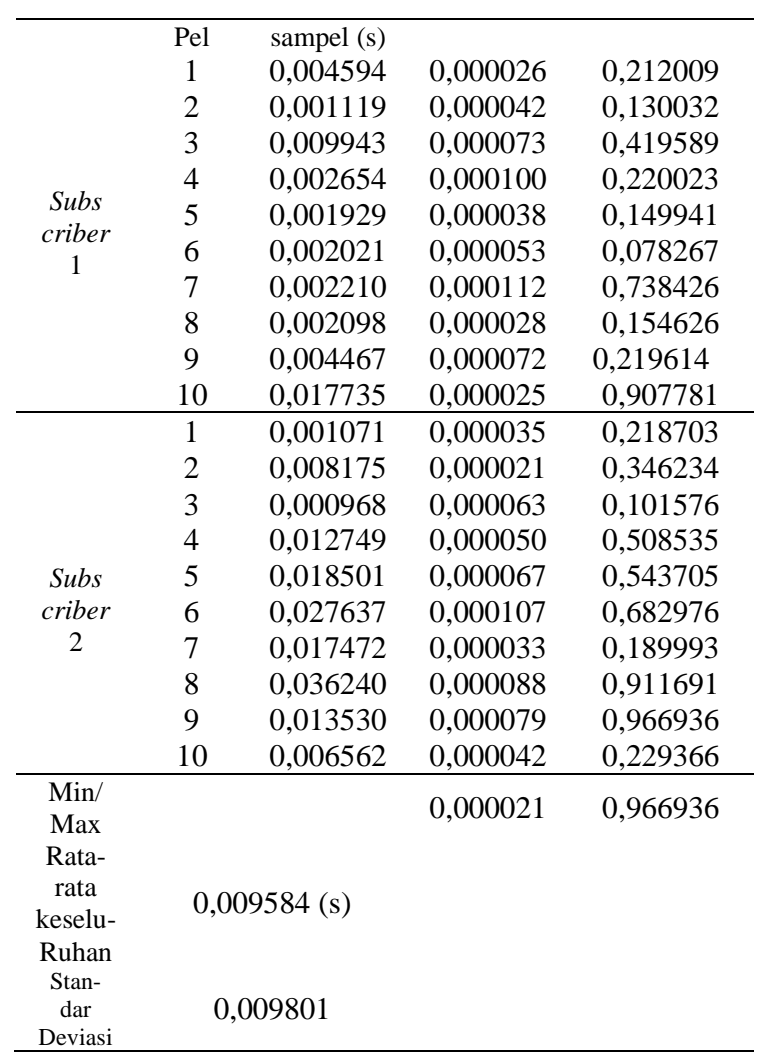

Untuk rata - rata waktu proses enkripsi pada QoS 1 menghasilkan 0,009584 s. Dengan waktu minimum pengiriman antara kedua subscriber adalah 0,000021 s dan waktu maksimum adalah $0,966936 \mathrm{~s}$, dengan standar deviasi sebesar 0,009801. Seperti yang dibahas pada sub bab sebelumnya dikarenakan pada QoS 1 terdapat tambahan sinyal kontrol yaitu PUBACK untuk memastikan bahwa data benar - benar sampai pada sisi penerima.

\section{b. Hasil Cross-correlation}

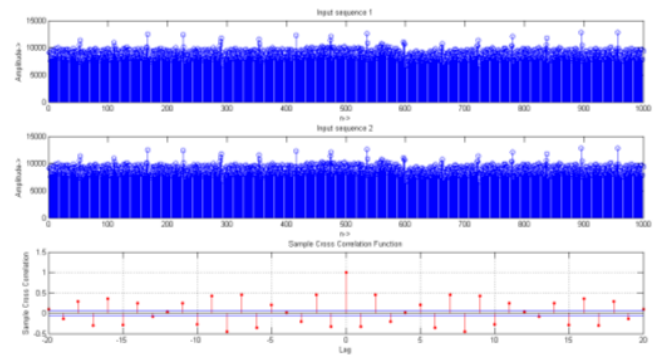

Gambar 25. Hasil cross-correlation subscriber 1 (QoS 1) 


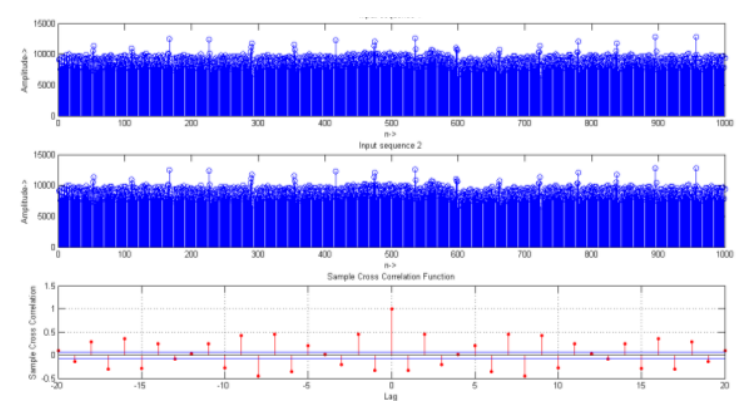

Gambar 26. Hasil cross-correlation subscriber 2 (QoS 1)

Hasil kedua subscriber menunjukkan pengiriman pada QoS 1 menghasilkan nilai 1 pada lag ke-0, hal ini dapat diartikan data yang dikirim dan diterima adalah sama atau tidak ada perbedaaan.

\section{KESIMPULAN}

Berdasarkan pengujian pengiriman yang telah dilakukan pada penelitian ini dapat disimpulkan sebagai berikut :

1. Penerapan fitur keamanan protokol MQTT dapat dilakukan dengan menggunakan protokol TLS (MQTTS.)

2. Penerapan MQTTS pada mosquitto (broker lokal) menggunakan metode enkripsi simetris, sehingga pemakaian kunci untuk semua klien sama dengan broker.

3. Penerapan MQTTS untuk pengiriman data pada bidang kesehatan (telehealthcare) dapat dilakukan, sebagaimana pada penelitian ini yang menggunakan sampel data EKG.

4. Hasil pengujian selisih besar paket sebelum dan setelah enkripsi menunjukkan selisih yang cukup jauh lebih besar. Tetapi, dengan demikian pengiriman data menjadi lebih aman.

5. Pada pengujian waktu yang dibutuhkan untuk proses enkripsi pada QoS 0 dan QoS 1 menunjukkan hasil 0,0007195 detik dan 0,009584 detik. Waktu pengiriman QoS 1 lebih lama dikarenakan adanya tambahan sinyal kontrol yaitu PUBACK pada QoS 1.

6. Pengujian integritas data menggunakan metode cross-correlation pada QoS 0 dan QoS 1 menunjukkan hasil 1 pada lag ke-0. Sehingga dapat diartikan pengririman data menggunakan MQTTS QoS 0 maupun QoS 1 tidak terjadi perubahan (sama).

Adapun saran untuk pengembangan penelitian ini adalah menerapkan protokol MQTTS pada broker online, sehingga proses transmisi dapat dilakukan dalam jarak yang lebih jauh. Selain itu, dapat dilakukan untuk pengujian keamanan protokol MQTTS terhadap serangan - serangan dari luar.

\section{DAFTAR PUSTAKA}

[1] M. B. Yassein, M. Q. Shatnawi, S. Aljwarneh and R. Al-Hatmi, "Internet of Things: Survey and open issues of MQTT protocol," 2017 International
Conference on Engineering \& MIS (ICEMIS), Monastir, 2017, pp. 1-6, doi: 10.1109/ICEMIS.2017.8273112.

[2] M. R. Bintami, Rancang Bangun Transmisi Data Heart Rate menggunakan Protokol MQTT, Surabaya: Universitas Dinamika, 2019.

[3] B. A. Setiawan, I. Puspasari, S. Solehuddin dan J. Jusak, "Implementasi Pengamanan Transmisi Sinyal EKG (Elektrokardiogram) secara Daring dengan Metode Anonimasi," Elkomika, vol. 7, pp. 85-96, 2019.

[4] A. Mishra, A. Kumari, P. Sajit dan P. Pandey, "Remote Web Based ECG Monitoring Using MQTT Protocol," International Journal of Advance Engineering and Research, vol. 5, no. 4, p. 1100, 2018.

[5] H. Lee, J. Lim dan T. Kwon, "MQTLS: Toward Secure MQTT Communication with an Untrusted Broker," International Conference on Information and Communication Technology Convergence (ICTC), p. 53, 2019.

[6] N. Nikolov and O. Nakov, "Research of Secure Communication of Esp32 IoT Embedded System to.NET Core Cloud Structure using MQTTS SSL/TLS," 2019 IEEE XXVIII International Scientific Conference Electronics (ET), Sozopol, Bulgaria, 2019, pp. 1-4, doi: 10.1109/ET.2019.8878636.

[7] A. Febiyanto, Pengukuran dan Pengamatan Sinyal Electrocardiogram menggunakan Raspberry dengan Tampilan Aplikasi Mobile, Surabaya: Universitas Dinamika, 2019.

[8] B. A. Setiawan, Anonimasi Sinyal EKG (Elektrokardiogram) untuk Keamanan Transmisi Data pada Sebuah Node Sensor, Surabaya: Universitas Dinamika, 2018. 